\title{
Intron-3 Retention/Splicing Controls Neuronal Expression of Apolipoprotein E in the CNS
}

\author{
Qin Xu, ${ }^{1,2}$ David Walker, ${ }^{1}$ Aubrey Bernardo, ${ }^{1}$ Jens Brodbeck, ${ }^{1,2}$ Maureen E. Balestra, ${ }^{1}$ and Yadong Huang ${ }^{1,2,3,4}$ \\ ${ }^{1}$ Gladstone Institute of Neurological Disease and ${ }^{2}$ Gladstone Institute of Cardiovascular Disease, San Francisco, California 94158, and Departments of \\ ${ }^{3}$ Pathology and ${ }^{4}$ Neurology, University of California, San Francisco, California 94143
}

\begin{abstract}
Neuronal expression of apolipoprotein (apo) E4 may contribute to the pathogenesis of Alzheimer's disease (AD). In studying how apoE expression is regulated in neurons, we identified a splicing variant of apoE mRNA with intron-3 retention (apoE-I3). ApoE-I3 mRNA was detected in neuronal cell lines and primary neurons, but not in astrocytic cell lines or primary astrocytes, from humans and mice by reverse transcription (RT)-PCR. In both wild-type and human apoE knock-in mice, apoE-I3 was found predominantly in cortical and hippocampal neurons by in situ hybridization. Cell fractionation and quantitative RT-PCR revealed that over $98 \%$ of the apoE-I3 mRNA was retained in the nucleus without protein translation. In transfected primary neurons, apoE expression increased dramatically when intron-3 was deleted from a genomic DNA construct and decreased markedly when intron-3 was inserted into a cDNA construct, suggesting that intron-3 retention/splicing controls apoE expression in neurons. In response to excitotoxic challenge, the apoE-I3 mRNA was markedly increased in morphologically normal hippocampal neurons but reduced in degenerating hippocampal neurons in mice; apoE mRNA showed the opposite pattern. This apparent precursor-product relationship between apoE-I3 and apoE mRNA was supported by a transcriptional inhibition study. Thus, neuronal expression of apoE is controlled by transcription of apoE-I3 under normal conditions and by processing of apoE-I3 into mature apoE mRNA in response to injury.
\end{abstract}

Key words: apolipoprotein E; Alzheimer’s disease; excitotoxicity; gene regulation; intron retention; knock-in mice

\section{Introduction}

Apolipoprotein (apo) E is a multifunctional protein with central roles in lipid metabolism and neurobiology. It has three common isoforms (apoE2, apoE3, and apoE4) with different effects on lipid and neuronal homeostasis (Mahley, 1988; Weisgraber and Mahley, 1996; Huang et al., 2004; Huang, 2006a,b; Mahley et al., 2006). ApoE4 is a major risk factor or susceptibility gene that increases the occurrence and lowers the age of onset of the sporadic and some familial forms of Alzheimer's disease (AD) (Corder et al., 1993; Saunders et al., 1993; Strittmatter et al., 1993). ApoE4 is also associated with earlier onset, progression, or severity of head trauma (Teasdale et al., 1997), stroke (Alberts et al., 1995; Slooter et al., 1997), Parkinson's disease (Li et al., 2004), multiple sclerosis (Schmidt et al., 2002; Kantarci et al., 2004), and amyotrophic lateral sclerosis (Moulard et al., 1996; Lacomblez et al., 2002). Although the mechanisms underlying the pathogenic effects of apoE4 in $\mathrm{AD}$ and other neurodegenerative disorders are still poorly understood, emerging data strongly suggest that apoE4, with its multiple cellular origins and multiple structural and biophysical properties, contributes to these diseases by inter-

Received April 17, 2007; revised Nov. 7, 2007; accepted Dec. 15, 2007

This work was supported in part by Grants P01 AG022074 and RR18928 from the National Institutes of Heath. We thank Drs. Robert W. Mahley, Karl H. Weisgraber, and Lennart Mucke for critical reading of this manuscript, Karina Fantillo for manuscript preparation, Stephen Ordway and Gary Howard for editorial assistance, John C. W. Carroll for graphics, and Chris Goodfellow for photography.

Correspondence should be addressed to Dr. Yadong Huang, Gladstone Institute of Neurological Disease, 1650 Owens Street, San Francisco, CA 94158. E-mail: yhuang@gladstone.ucsf.edu.

DOI:10.1523/JNEUROSCI.3253-07.2008

Copyright $\odot 2008$ Society for Neuroscience $\quad$ 0270-6474/08/281452-08\$15.00/0 acting with different factors through various pathways (Weisgraber and Mahley, 1996; Huang et al., 2004, 2006a,b; Mahley et al., 2006).

ApoE is produced by several types of cells in the CNS, including astrocytes (Pitas et al., 1987; Grehan et al., 2001) and activated microglia (Uchihara et al., 1995; Xu et al., 2000). Neuronal expression of apoE has been controversial (Page et al., 1998; Xu et al., 1999; Nishio et al., 2003; Harris et al., 2004b; Huang et al., 2004, 2006a,b). Using knock-in mice in which enhanced green fluorescent protein (EGFP) cDNA was inserted into the mouse apoE locus immediately after the translation initiation site (EGF$\mathrm{P}_{\mathrm{apoE}}$ reporter mice), we laid this controversy to rest by demonstrating that neurons express apoE in response to injury (Xu et al., 2006). The diverse cellular pattern of expression implies multiple functions of apoE. ApoE derived from different cellular sources probably has distinct roles in both physiological and pathophysiological pathways, influencing its effects on $\mathrm{AD}$ pathology (Huang et al., 2004, 2006a,b; Mahley et al., 2006). For example, astrocyte-derived apoE3 and apoE4 have different effects on the production, deposition, and clearance of $\mathrm{A} \beta$ (Wisniewski et al., 1994; Bales et al., 1999; Holtzman et al., 2000; Ye et al., 2005). Neuron-derived apoE3 and apoE4 differ in their susceptibility to proteolysis and in their effects on mitochondrial function, tau phosphorylation, lysosomal leakage, neurodegeneration, androgen receptor deficiency, and cognitive decline (Tolar et al., 1997, 1999; Raber et al., 1998, 2002; Buttini et al., 1999, 2002; Tesseur et al., 2000; Huang et al., 2001; Ji et al., 2002; Harris et al., 2003, 2004a; Brecht et al., 2004; Chang et al., 2005). Thus, understand- 
Table 1. Primers used in ApoE-13 studies

\begin{tabular}{|c|c|}
\hline Primer & Sequence \\
\hline \multicolumn{2}{|c|}{ Human apoE-I3/apoE RT-PCR primers } \\
\hline P1 (in human exon 1) & CAGCGGAGGTGAAGGACGT \\
\hline P2 (in human intron 3 ) & AGAGGCCGAGAGAAGGAGAC \\
\hline P3 (in human exon 4) & TTGTTCCTCCAGTTCCGATTTGTA \\
\hline \multicolumn{2}{|c|}{ Mouse apoE-I3/apoE RT-PCR primers } \\
\hline P1 (in mouse exon 1) & GCTCAGACCCTGGAGGCTAA \\
\hline P2 (in mouse intron 3) & TGGGCTACACACTAATTGAGAAA \\
\hline P3 (in mouse exon 4) & CTGTTCCTCCAGCTCCTTTTTGTA \\
\hline \multicolumn{2}{|c|}{ Mouse apoE-I3 3'-RACE primer } \\
\hline \multicolumn{2}{|c|}{ Mouse apoE-13 5'-RACE primer } \\
\hline mApoE-2681-2 & TGGGCTACACACTAATTGAGAAA \\
\hline \multicolumn{2}{|c|}{ Human apoE-I3 3'-RACE primer } \\
\hline hApoE-3499-1 & GGCTGGTCTTGAACTTCTGG \\
\hline \multicolumn{2}{|c|}{ Human apoE-I3 5'-RACE primer } \\
\hline hApoE-3649-2 & AGAGGCCGAGAGAAGGAGAC \\
\hline \multicolumn{2}{|c|}{ Human apoE-I3 gRT-PCR primers } \\
\hline 13-mRNA-77-1 & GCGTTGCTGGTCACATTCCT \\
\hline I3-mRNA-324-2 & AGGGTCAAGGGCCAGGATG \\
\hline \multicolumn{2}{|c|}{ Human apoE qRT-PCR primers } \\
\hline ApoE-3F & CCCAGGTCACCCAGGAACT \\
\hline ApoE- $4 B$ & TCCGATTTGTAGGCCTTCAACT \\
\hline \multicolumn{2}{|c|}{ Human GAPDH gRT-PCR primers } \\
\hline H-GAPDH-1 & AACAGCGACACCCATCCTC \\
\hline H-GAPDH-2 & CATACCAGGAAATGAGCTTGACAA \\
\hline \multicolumn{2}{|c|}{ Mouse GAPDH qRT-PCR primers } \\
\hline M-GAPDH-1 & GTCTCCTGCGACTTCAGC \\
\hline M-GAPDH-2 & TCATTGTCATACCAGGAAATGAGC \\
\hline \multicolumn{2}{|c|}{ Mouse U3B snoRNA qRT-PCR primers } \\
\hline M-U3B-1 & TGTAGAGCACCCGAAACCAC \\
\hline M-U3B-2 & GTCCACTCAGACTGCGTTCC \\
\hline
\end{tabular}

ing how apoE expression is regulated in different types of cells in the brain during aging and in response to various insults should provide fundamental insights into the varied effects of apoE isoforms in neurobiology and neurodegenerative disorders, including $\mathrm{AD}$.

Previously, intron retention was identified as a molecular mechanism to regulate gene expression and protein translation in mammalian cells (Kan et al., 2002; Galante et al., 2004). Many studies suggest that most transcripts with intron retention are restricted in the nuclei for degradation or have a regulatory role for its own or other transcripts (Cui et al., 2004; Mansilla et al., 2005; Qin et al., 2005). In the current study, we identified a splicing variant of apoE mRNA with intron-3 retention (apoE-I3) specifically in neurons. Both in vitro and in vivo studies indicate that intron-3 retention/splicing controls neuronal expression of apoE in the CNS.

\section{Materials and Methods}

Reagents and animals. Minimum essential medium (MEM), Opti-MEM, and fetal bovine serum were from Invitrogen (Carlsbad, CA). ECL was from GE Healthcare Bio-Sciences (Piscataway, NJ). Polyclonal goat antihuman apoE antibody was from Calbiochem (La Jolla, CA). Kainic acid was from Sigma (St. Louis, MO). Wild-type mice were from The Jackson Laboratory (Bar Harbor, ME). Human apoE3 or apoE4 knock-in mice were from Taconic (Hudson, NY). EGFP $\mathrm{apoE}_{\text {e }}$ reporter mice were generated in our laboratory and reported previously (Xu et al., 2006). All mice were weaned at $21 \mathrm{~d}$ of age, housed in a barrier facility at the Gladstone Animal Core with a $12 \mathrm{~h}$ light/dark cycle, and fed a chow diet containing $4.5 \%$ fat (Ralston Purina, St. Louis, MO).

Determination of the full-length cDNA of apoE-I3 by $3^{\prime}$ - and 5' -RACE. Human and mouse brain total RNA from Ambion (Austin, TX) was used
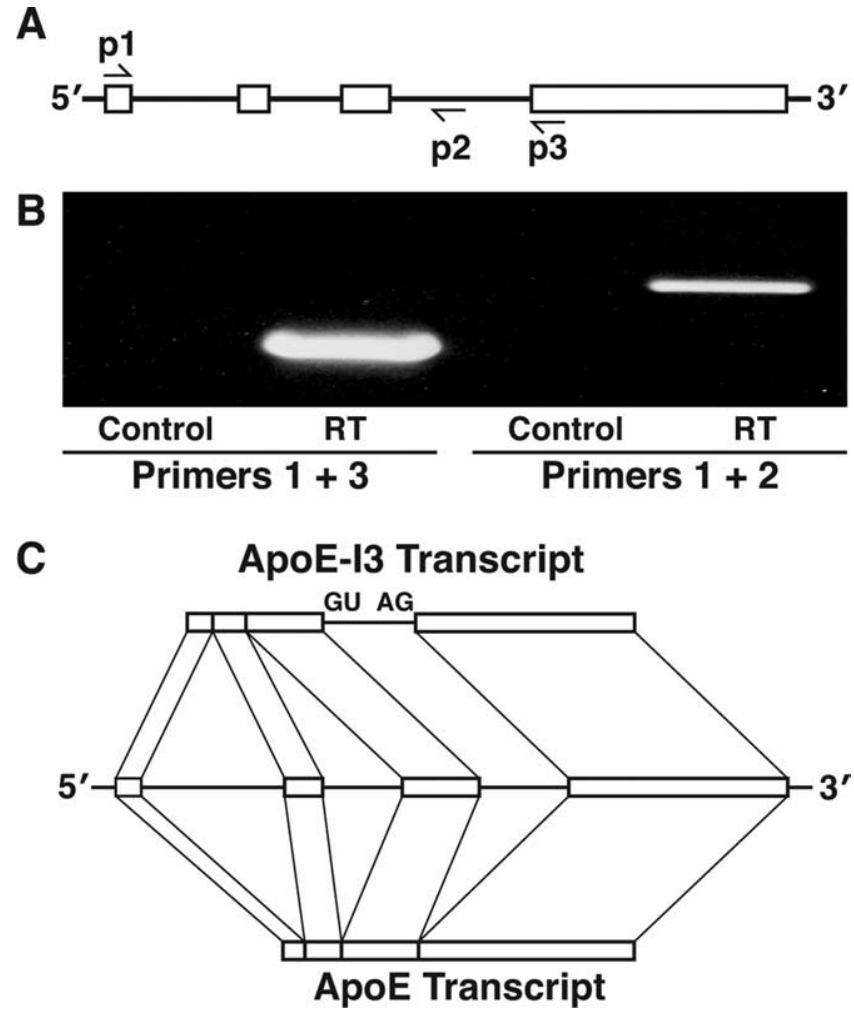

Figure 1. Identification of apoE-I3 transcript in human and mouse brain total mRNA. $A$, The apoE gene structure, including four exons and three introns, and the positions of primers 1,2 , and 3. B, The RT-PCR results of primers 1 and 3 or primers 1 and 2 using mouse brain total RNAs as templates. Omission of the reverse transcriptase in the RT reaction was used as a negative control. C, Organization of apoE-I3 mRNA and apoE mRNA. GU and AG indicate the $5^{\prime}$ and $3^{\prime}$ splicing sites of intron-3 of apoE, respectively.

as templates in the reverse transcription (RT) reaction. For $3^{\prime}$-rapid amplification of cDNA ends ( $3^{\prime}$-RACE), an anchored oligo-dT primer (ordered from Invitrogen) was used as reverse transcription primer. After the RT reaction, a forward primer corresponding to a sequence within intron-3 and a backward primer corresponding to the anchor sequence of the RT primer was used to amplify the $3^{\prime}$-end of apoE-I3. The PCR products were subcloned into a topoisomerase (TOPO) vector (Invitrogen) and sequenced. A 5'-RACE kit (Ambion) was used to detect the 5 '-end of apoE-I3. Through the RNA ligation reaction, an anchored poly $\mathrm{G}$ sequence was added to the $5^{\prime}$-end of different RNAs from human or mouse brains. The RT reaction was then performed with an oligo-dT primer, and the $5^{\prime}$-end of apoE-I3 was amplified by a forward primer corresponding to the anchor sequence and a backward primer corresponding to a sequence within intron-3. The PCR products were then subcloned into a TOPO vector and sequenced.

Cell cultures. Neuro-2a, U87, and C6 cells (American Type Culture Collection, Manassas, VA) were maintained at $37^{\circ} \mathrm{C}$ in a humidified $5 \%$ $\mathrm{CO}_{2}$ incubator in MEM containing 10\% FBS supplemented with nonessential amino acids, sodium pyruvate, and penicillin/streptomycin. Neuro-2a cells stably transfected with human apoE3 or apoE4 genomic DNA were established in our laboratory and reported previously (Harris et al., 2004b). Human neuronal precursor NT2/D1 cells were kindly provided by Dr. Virginia M.-Y. Lee (University of Pennsylvania School of Medicine, Philadelphia, PA) and maintained in Opti-MEM-I (Invitrogen) containing 5\% FBS and penicillin/streptomycin. The cells were treated with retinoic acid to induce differentiation into NT2 neurons.

Primary cultures of cortical or hippocampal neurons were prepared from postnatal day 1 (P1) wild-type mice or rats (Harris et al., 2004b). Primary astrocytes were prepared from P3 wild-type mice (Harris et al., 2004b). As determined by immunostaining with cell-specific antibodies, $>95 \%$ of cells in 10 - to 14 -d-old cortical cultures in vitro are positive for 
neuron-specific enolase, and $>95 \%$ of cells in 6- to 10-d-old astrocyte cultures in vitro are positive for glial fibrillary acidic protein (GFAP).

The primary neurons were treated with 100 $\mathrm{ng} / \mathrm{ml}$ actinomycin $\mathrm{D}$ for $6 \mathrm{~h}$ to block transcription. The cells were then treated with C6conditioned medium for $24 \mathrm{~h}$, as described previously (Harris et al., 2004b) and harvested for additional Western or quantitative fluorogenic RT (qRT)-PCR assay of apoE.

Preparation of cell lysates and Western blotting. Cultured cells transfected with or without various apoE constructs were grown to $80 \%$ confluence in six-well plates. The cells were harvested, lysed in ice-cold lysis buffer $(50 \mathrm{~mm}$ Tris/HCl, pH 8.0, $150 \mathrm{~mm} \mathrm{NaCl,} \mathrm{0.1 \%} \mathrm{SDS,} 1 \%$ Nonidet P-40, $0.5 \%$ sodium deoxycholate, and a mixture of protease inhibitors) for $30 \mathrm{~min}$, and centrifuged at 13,000 rpm for $15 \mathrm{~min}$. The same amount of proteins in the supernatant was subjected to SDS-PAGE and detected by anti-apoE Western blotting (Huang et al., 2001). The apoE bands were scanned and quantified (Harris et al., 2004b).

Analyses of apoE and apoE-I3 mRNA by RT$P C R$ and $q R T-P C R$. Total RNA was isolated from cell lines with the RNeasy Mini Kit (Qiagen, Valencia, CA) and from mouse brains with Triazol (Invitrogen). RT-PCR of apoE and apoE-I3 was performed with $1 \mu \mathrm{g}$ of total RNA and Superscript First-Strand Synthesis System kits (Invitrogen). All primers are listed in Table 1.

ApoE-I3 and apoE mRNA levels were determined in triplicate by qRTPCR with glyceraldehyde-3-phosphate dehydrogenase (GAPDH) mRNA as an internal control. RT reactions were performed as described above. qRT-PCRs consisted of $10 \mu \mathrm{l}$ of diluted cDNA reaction mixture (equivalent to $4.0 \mathrm{ng}$ of RNA template), $12.5 \mu \mathrm{l}$ of SYBR Green PCR master mix (Applied Biosystems, Foster City, CA), and $300 \mathrm{~nm}$ of each forward and backward primer in a final volume of $25 \mu \mathrm{l}$. Serial dilution of pooled cDNA samples from all cells or tissues were used to generate standard curves to determine the relative levels of specific mRNAs in individual samples. ApoE-I3 mRNA levels were then calculated and normalized to the internal GAPDH mRNA standards. In some experiments, mRNAs of apoE and apoE-I3 were determined in the nucleus and cytosol separately, using U3B small nucleolar RNA (snoRNA) as a control for successful separation of the cytosolic and nuclear fractions (Speckmann et al., 1999).

Kainic acid injections. Kainic acid crosses the blood-brain barrier and induces excitotoxic CNS injury, particularly in the hippocampus and neocortex (Masliah et al., 1997). Wild-type and human apoE3 or apoE4 knock-in mice at 4-6 months of age were injected intraperitoneally with kainic acid (Sigma) dissolved in saline $(0.9 \%)$ at $25 \mathrm{mg} / \mathrm{kg}$ body weight in one dose, as described previously (Buttini et al., 1999). Mice were killed $1-6 \mathrm{~d}$ after the injection.

Preparation of mouse brain tissues. Brains from kainic acid-treated wild-type and human apoE knock-in mice and untreated controls were collected after a 2 min transcardial perfusion with PBS. One hemibrain from each mouse was used for purifying total RNA as described above. The other hemibrain was fixed in $3 \%$ paraformaldehyde, embedded in paraffin, and cut into $7 \mu \mathrm{m}$ sections. Hematoxylin and eosin (H\&E) and silver staining were used to assess the severity of neurodegeneration after kainic acid treatment.

Laser-capture microdissection of hippocampal neurons. Homozygous EGFP $_{\text {apoE }}$ reporter mice were cross-bred with homozygous human apoE4 knock-in mice to generate mice with one human apoE4-targeted allele and one EGFP-targeted allele (apoE4/EGFP ${ }_{\text {apoE }}$ ). The apoE4/EGF$\mathrm{P}_{\mathrm{apoE}}$ mice at 4-5 months of age were injected intraperitoneally with

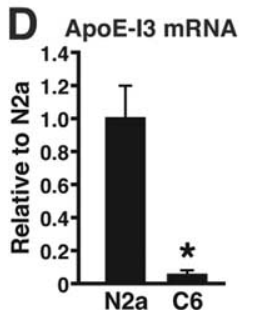

B

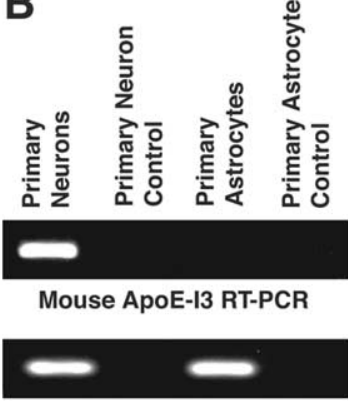

Mouse GAPDH RT-PCR

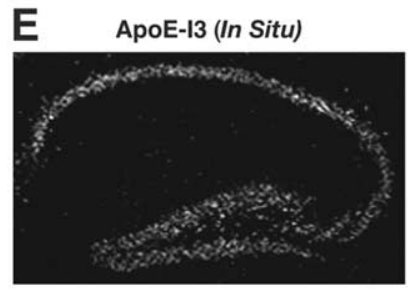

F ApoE-I3 (In Situ + RNase)

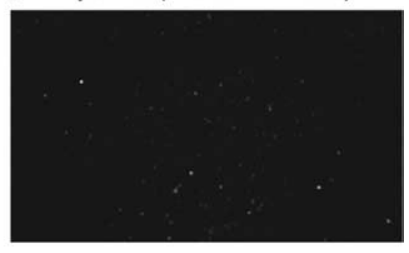

C

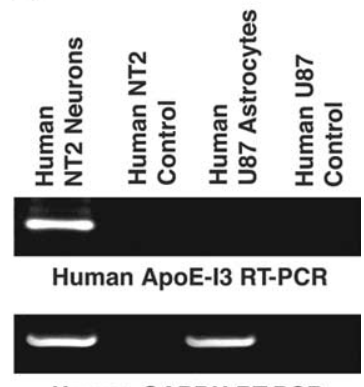

Human GAPDH RT-PCR

Figure 2. Neuron-specific expression of apoE-I3.A, RT-PCR of mouse apoE-I3 and GAPDH using total RNA from mouse primary cortical or hippocampal neurons as RT templates. $\boldsymbol{B}, \mathrm{RT}-\mathrm{PCR}$ of mouse apoE-I3 and GAPDH using total RNA from mouse primary eurons or primary astrocytes as RT templates. C, RT-PCR of human apoE-I3 and GAPDH using total RNA from human NT2 neurons hippocampus of human apoE knock-in mice.

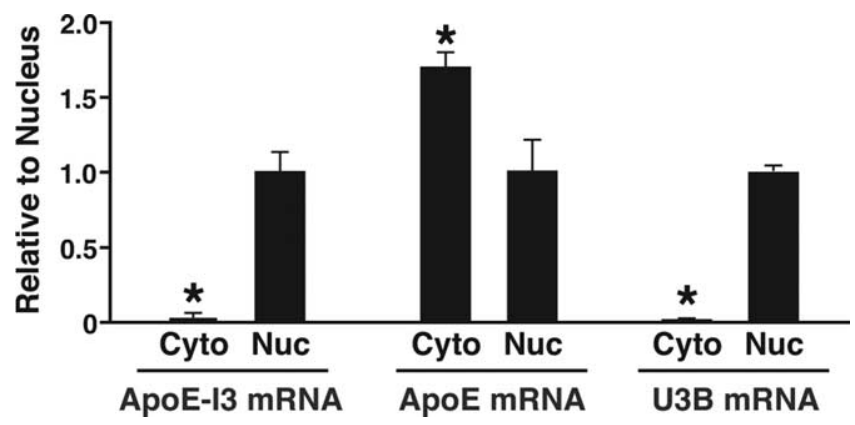

Figure 3. The apoE-I3 mRNA is retained in the nucleus. The apoE- $13 \mathrm{mRNA}$ levels in the nuclei (Nuc) and cytosol (Cyto) of Neuro-2a cells transfected with a human apoE genomic DNA construct were determined by qRT-PCR $\left(n=3 ;{ }^{*} p<0.001\right.$ vs nucleus). The apoE mRNA levels in the nuclei and cytosol of Neuro-2a cells transfected with a human apoE genomic DNA construct were determined by qRT-PCR ( $n=3 ;{ }^{*} p<0.01$ vs nucleus). The U3B small nucleolar mRNA levels in the nuclei and cytosol of Neuro-2a cells used above were determined by qRT-PCR ( $n=$ $3 ;{ }^{*} p<0.001$ vs nucleus).

kainic acid, as described above. Brains from kainic acid-treated apoE4/ $\mathrm{EGFP}_{\mathrm{apoE}}$ mice and untreated controls were collected and frozen at $-70^{\circ} \mathrm{C}$. The frozen brains were sectioned $(8 \mu \mathrm{m})$, fixed on glass slides, and stained with $1 \%$ neutral red. Approximately $300-400$ EGFP-positive CA1 neurons were collected from each kainic acid-treated apoE4/EGF$\mathrm{P}_{\text {apoE }}$ mouse by laser-capture microdissection (LCM) with an Arcturus (Mountain View, CA) laser-capture microdissection system. Similar numbers of EGFP-negative CA1 neurons were collected from each untreated control mouse. Cells were collected into CapSure Macro LCM Caps (Arcturus). Total RNA was isolated from the collected cells using the PicoPure RNA Isolation Kit (Arcturus). RT-PCR of apoE and apoE-I3 was performed as described above. RT-PCR of GFAP, an astrocyte marker, was used to assess neuronal cell purity.

In situ hybridization. RNA probes specific for mouse and human apoE-I3 mRNA are complementary to nucleotides 216-374 in intron-3 
A

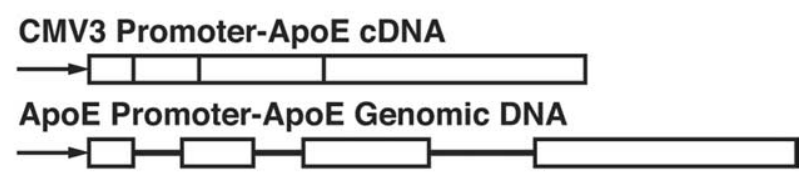

B

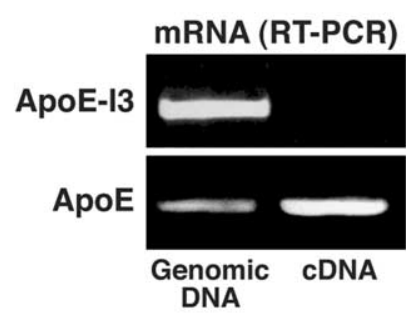

C

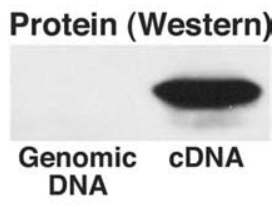

D
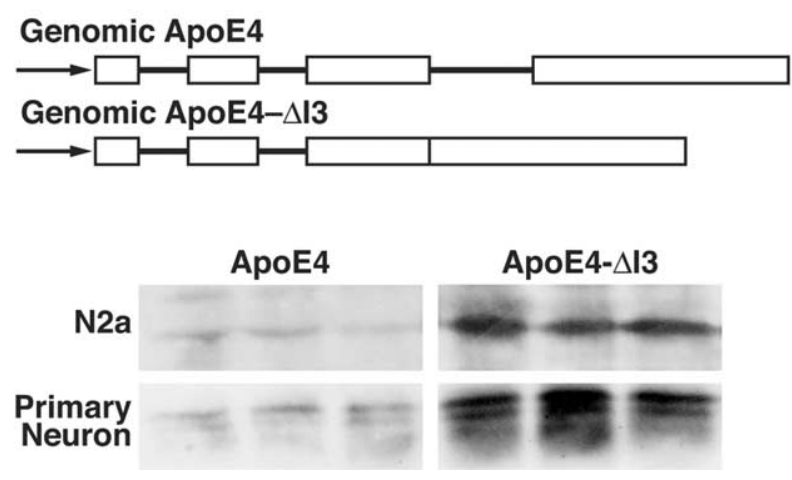

Figure 4. Intron-3 retention/splicing controls neuronal expression of apoE. $\boldsymbol{A}$, Schematic models of human apoE cDNA and genomic DNA constructs. $\boldsymbol{B}, \mathrm{RT}-\mathrm{PCR}$ of human apoE-I3 and apoE using total RNA isolated from Neuro-2a cells transfected with a human apoE4 cDNA or a genomic DNA construct as templates. C, ApoE Western blotting of cell lysates from Neuro-2a cells transfected with a human apoE4 cDNA or a genomic DNA construct. $D$, The human apoE4 or apoE4- $\Delta \mathrm{I} 3$ genomic DNA construct was transfected into Neuro-2a or rat primary hippocampal neurons. The intracellular apoE protein levels were determined by anti-apoE Western blotting and compared by calculating the ratio of apoE protein in apoE4- $\Delta \mathrm{I} 3$-transfected cells to that in apoE4-transfected cells (N2a, $4 \pm 1, n=6$; primary neuron, $5 \pm 1, n=6$ ).

of the mouse apoE gene and to nucleotides $425-580$ in intron- 3 of the human apoE gene, respectively. RNA probes specific for mouse and human apoE mRNA are complementary to nucleotides $228-283$ in the mouse apoE mRNA (NM_009696) and to the nucleotides 298-340 in the human apoE mRNA (NM_000041), respectively, which covers both exons 3 and 4 . All RNA probes were labeled with $\left[{ }^{33} \mathrm{P}\right] \mathrm{UTP}$ with an RNA transcription kit (Stratagene, La Jolla, CA). The labeled probes were purified through Micro Bio-Spin-30 chromatography columns (Bio-Rad, Hercules, CA). In situ hybridization was performed as described previously (Grehan et al., 2001). As a negative control, some slides were pretreated with $100 \mu \mathrm{g} / \mathrm{ml}$ RNase A and $50 \mathrm{U} / \mathrm{ml} \mathrm{T}_{1}$ RNase for $1 \mathrm{~h}$ at $37^{\circ} \mathrm{C}$ followed by five washes in PBS ( 5 min each).

Statistical analysis. A two-tailed $t$ test assuming equal variance was used for statistical analyses. $p<0.05$ was considered significant difference.

\section{Results}

A novel apoE-I3 transcript in mouse and human brains To measure apoE mRNA expression in mouse brains, we performed RT-PCR with a pair of primers located in exons 1 and 4 (Fig. $1 A, \mathrm{p} 1, \mathrm{p} 3, B$ ) and control primers located in exon 1 and intron-3 (Fig. $1 A, \mathrm{p} 1, \mathrm{p} 2$ ). Surprisingly, the control primers generated an unexpected DNA product that disappeared when the reverse transcriptase was omitted (Fig. $1 B$ ), indicating that it was a product from reverse transcription of an mRNA, but not from genomic DNA. After exclusion of primer contamination and en-

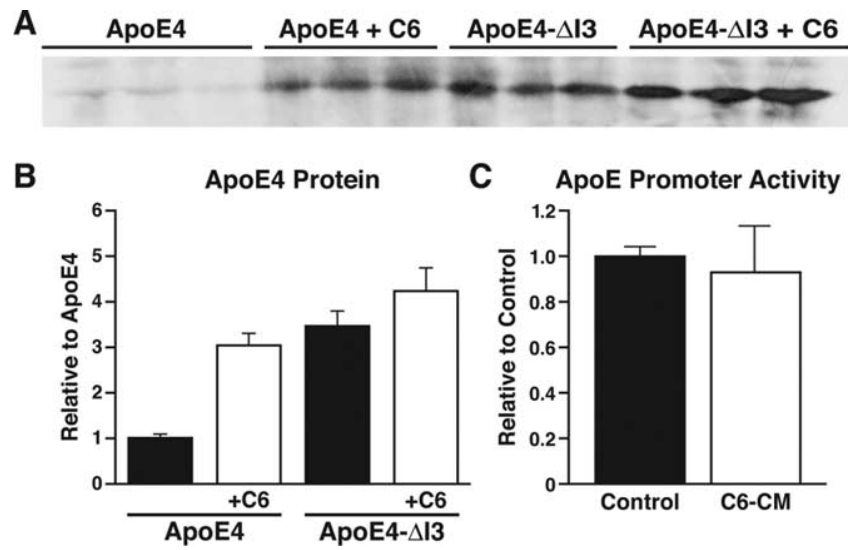

Figure 5. Astroglial regulation of neuronal apoE expression acts via the processing of apoEI3. $\boldsymbol{A}$, Neuro-2a cells were transfected with apoE4 or apoE4- $\Delta / 3$ genomic DNA construct in the presence or absence of (6-conditoned medium. The cells were lysed $24 \mathrm{~h}$ after transfection as described in Materials and Methods. The same amounts of total proteins were subjected to SDS-PAGE and detected by anti-apoE Western blotting. $\boldsymbol{B}$, Quantitative results of $\boldsymbol{A}$, as determined by scanning the apoE bands, were reported as relative to apoE4 $(n=3)$. $C$, The effect of astrocyte-conditioned medium on apoE promoter activity was determined in Neuro-2a cells stably transfected with an apoE promoter-alkaline phosphatase reporter construct $(n=9)$.

dogenous priming (with an EndoFree RT kit; Ambion), the unexpected product was still present (data not shown). Its size ( $\sim 600$ bp) suggested that it was not from apoE pre-mRNA containing exons $1-3$ and introns $1-3(\sim 1.6 \mathrm{~kb})$. Sequencing analysis revealed the sequences of exons $1-3$ and intron- 3 before primer 2 (Fig. 1A). Similar results were obtained with total RNA from human brain (data not shown). Thus, the product appeared to be a splicing variant containing at least portion of the intron-3 sequence.

To identify the ends of the potential splicing variant, we used $3^{\prime}$ - and $5^{\prime}$-RACE. Sequencing analyses of $>10$ clones of both $3^{\prime}$ and $5^{\prime}$-RACE products demonstrated a novel transcript that differed from apoE mRNA only by having the intron-3 retention (Fig. 1C). This apoE-I3 transcript was present in mouse brains and at a relatively higher level in human brains as determined by RT-PCR (data not shown). BLAST (basic local alignment search tool) searches of the expression sequence tag database with the human apoE intron-3 sequence identified two apoE-related sequences (AI147021 and AA902874). Both contained part of the intron-3 sequence of the apoE gene, supporting the existence of the apoE-I3 transcript.

\section{ApoE-I3 is neuron specific in the CNS}

RT-PCR specific for apoE-I3 revealed that it was transcribed in mouse primary cortical and hippocampal neurons (Fig. $2 A$ ), but not in mouse primary astrocytes (Fig. $2 B$ ). ApoE-I3 was also expressed in neuronal cell lines, including differentiated human NT2 neurons (Fig. 2C) and mouse neuroblastoma Neuro-2a cells (data not shown), but not in astrocytic cell lines, such as human U87 (Fig. 2C). Furthermore, as shown by real-time qRT-PCR, significant levels of human apoE-I3 mRNA were present in Neuro-2a cells, but not C6 cells, after transfection with a human apoE genomic DNA construct containing $5 \mathrm{~kb}$ of $5^{\prime}$-flanking region, four exons, three introns, and $8 \mathrm{~kb}$ of $3^{\prime}$-flanking region of the apoE gene (Fig. 2D). In situ hybridization with an apoEI3-specific probe detected a signal highlighting the hippocampal pyramidal neurons in human apoE knock-in mice (Fig. 2E) and wild-type mice (data not shown). As a negative control, pretreatment of brain sections with RNase abolished the apoE-I3 signal 
(Fig. 2F). Cortical neurons were also positive for the apoE-I3 signal (data not shown).

ApoE-I3 is retained in the nucleus and is not translated

In Neuro-2a cells stably transfected with an apoE genomic DNA, $>98 \%$ of apoE-I3 mRNA was retained in the nucleus, as shown by qRT-PCR, whereas $\sim 60 \%$ of apoE mRNA was in the cytosol (Fig. 3). Importantly, $>98 \%$ of U3B small nucleolar mRNA was also found in the nuclear fraction (Fig. 3), indicating the purity of nuclear and cytosolic fractions (Speckmann et al., 1999). We then examined the potential protein sequence encoded by apoE-I3 mRNA. Because there is a stop codon at the junction of exon 3 and intron-3 in the apoE-I3 transcript, the expected translation product was a short peptide containing the first 60 aa of apoE. Extensive anti-apoE Western blotting with various polyclonal and monoclonal antibodies, which recognize the $\mathrm{N}$ terminus of apoE, failed to reveal such a peptide in different neuronal cells transfected with or without apoE genomic DNA or in mouse and human brains (data not shown).

\section{Intron-3 retention/splicing controls neuronal expression of apoE}

To determine the role of intron-3 in neuronal expression of apoE, we measured apoE expression in Neuro-2a cells transfected with a cDNA or a genomic DNA construct (Fig. 4A). ApoE was expressed at much higher levels in cells transfected with cDNA (Fig. $4 B, C)$, whereas apoE-I3 was expressed only in cells transfected with genomic DNA (Fig. $4 B$ ). When intron-3 was deleted from the apoE genomic DNA construct (apoE4- $\Delta \mathrm{I} 3$ ) (Fig. $4 D$ ), apoE expression was fourfold to fivefold higher in Neuro-2a and rat primary hippocampal neurons transfected with that construct than in cells transfected with the wild-type apoE4 genomic DNA construct (Fig. 4D). And when intron-3 was inserted into the apoE cDNA (apoE-I3-cDNA), the apoE expression level in cells transfected with that construct was $\sim 30 \%$ of that in cells transfected with wild-type apoE-cDNA (data not shown). Thus, intron-3 is associated with a low level of apoE expression in neuronal cells.

\section{Astroglia regulate neuronal apoE expression through the processing of apoE-I3}

Previously, we showed that astrocyte-conditioned medium upregulates apoE expression in transfected Neuro-2a cells and mouse primary neurons (Fig. 5A, six left lanes, $B$ ) (Harris et al., 2004b). However, astrocyte-conditioned medium did not significantly alter apoE promoter activity in an alkaline phosphatase reporter assay (Fig. 5C), and removal of intron-3 from the apoE genomic DNA abolished the regulatory role of the conditioned medium (Fig. 5A, six right lanes, $B$ ). Thus, upregulation of neuronal apoE expression by an astrocytic factor (or factors) likely reflects increased processing of apoE-I3.

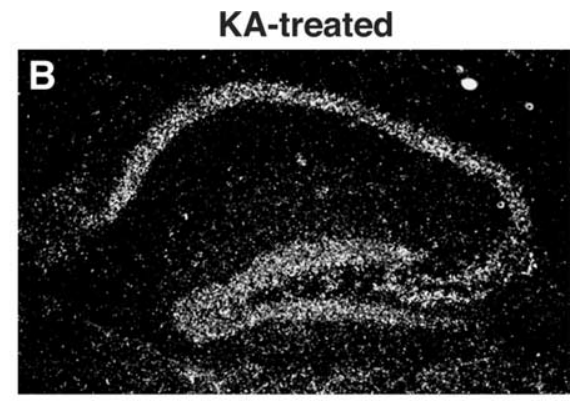

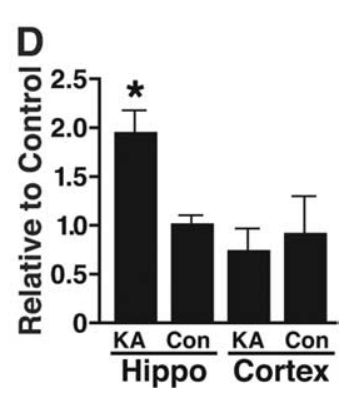

$1: 125$

$1: 25$
Figure 6. Expression of apoE-I3 in mouse brains in response to excitotoxic injury induced by kainic acid (KA). $\boldsymbol{A}, \boldsymbol{B}$, In situ hybridization of apoE-I3 mRNA in control $(\boldsymbol{A})$ and KA-treated $(\boldsymbol{B})$ human apoE knock-in mice. $\boldsymbol{C}, \mathrm{RT}-\mathrm{PCR}$ of apoE-I3 using a serial dilution of total RNA from the brains of KA-treated and untreated mice as templates. $\boldsymbol{D}, \mathrm{qRT}-\mathrm{PCR}$ of apoE-I3 in the hippocampus dilution of total RNA from the brains of KA-treated and untreated mice as templates. $D$, qRT-PCR of apoE-I3 in th
(Hippo) and cortex of control (Con) and KA-treated mice ( $n=3 ;{ }^{*} p<0.001$ vs the corresponding control).

\section{Expression and processing of apoE-I 3 is regulated by neuronal injury in the hippocampus}

To determine whether apoE-I3 processing is involved in the control of apoE expression by neurons in response to excitotoxic injury (Boschert et al., 1999; Xu et al., 2006), we treated human apoE knock-in mice with kainic acid and assessed neuronal injury by $\mathrm{H} \& \mathrm{E}$ and silver staining. In situ hybridization demonstrated that excitotoxic stress dramatically increased apoE-I3 mRNA levels in morphologically normal hippocampal neurons (Fig. 6A,B). RT-PCR analyses using a serial dilution of cDNA templates demonstrated higher levels of apoE-I3 mRNA in the brains of treated mice than in controls (Fig. 6C). qRT-PCR demonstrated a twofold increase of apoE-I3 expression in the hippocampus, but not in the cortex (Fig. $6 D$ ).

In degenerating hippocampal CA1 neurons in the treated mice, however, apoE-I3 mRNA disappeared, although it was still present in uninjured CA3 neurons and dentate gyrus granular cells (Fig. $7 \mathrm{~B}, \mathrm{C}$ ). In contrast, apoE mRNA was clearly present in the degenerating CA1 neurons but not in CA3 and dentate gyrus granular cells (Fig. $7 \mathrm{~A}, \mathrm{C}$ ). Thus, in response to excitotoxic stress, apoE-I3 expression increased in neurons with normal morphology, but disappeared in degenerating neurons. Conversely, apoE mRNA was expressed in degenerating neurons but not in normal neurons, as reported previously (Xu et al., 2006).

We then compared the expression of apoE-I3 and apoE mRNA by RT-PCR in CA1 neurons collected by laser-capture microdissection from untreated and kainic acid-treated apoE4/ $\mathrm{EGFP}_{\text {apoE }}$ reporter mice, in which one apoE allele is targeted apoE4 and the other is targeted EGFP (Xu et al., 2006). In these mice, neurons express EGFP and apoE in response to injury (Xu et al., 2006). The EGFP-negative CA1 neurons collected from untreated apoE4/EGFP ${ }_{\text {apoE }}$ mice by laser-capture microdissection expressed apoE-I3 mRNA, but not apoE mRNA, as determined by RT-PCR (Fig. 7D). However, the EGFP-positive CA1 neurons collected from kainic acid-treated apoE4/EGFP ${ }_{\text {apoE }}$ mice expressed apoE mRNA, but not apoE-I3 mRNA (Fig. 7E). Impor- 


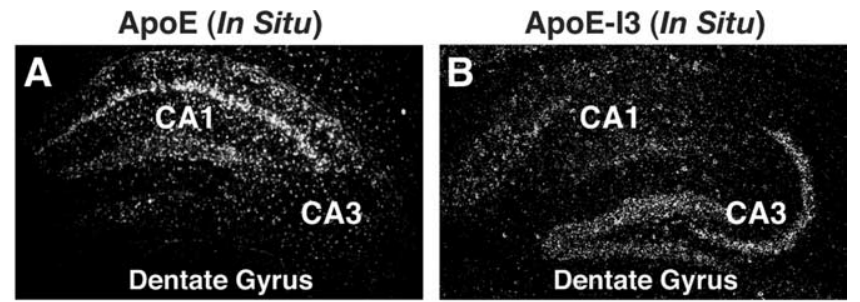

H\&E Staining
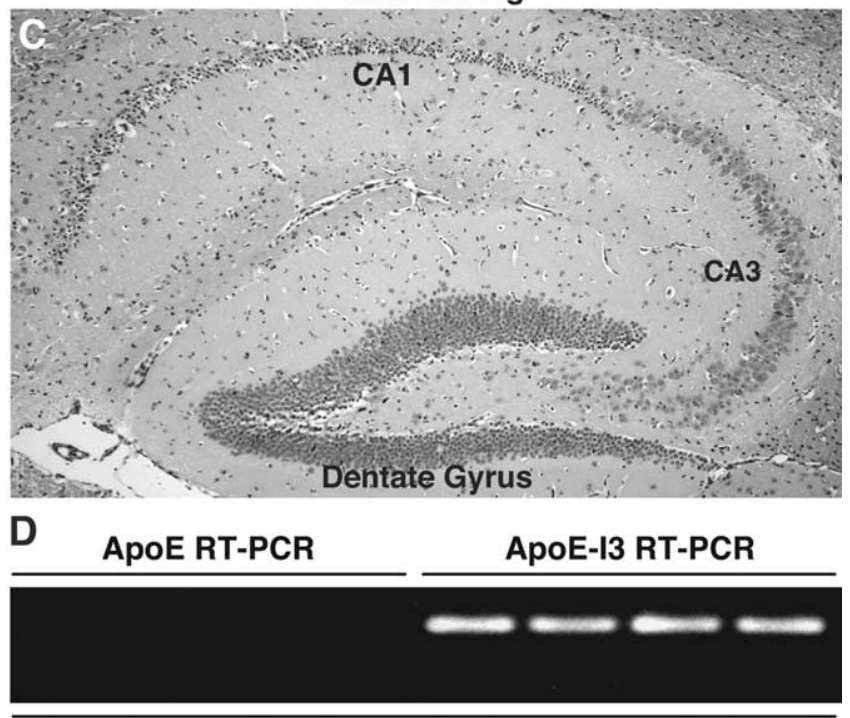

Neurons from untreated Mice

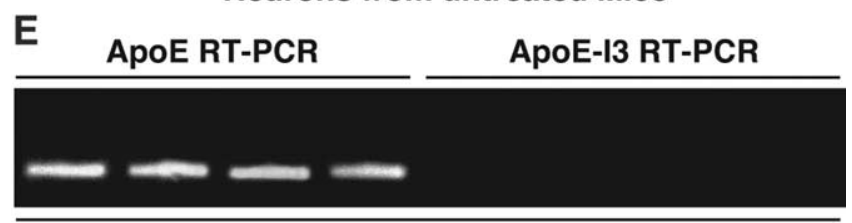

Neurons from KA-treated Mice

$\mathbf{F}$

\section{GAPDH RT-PCR}

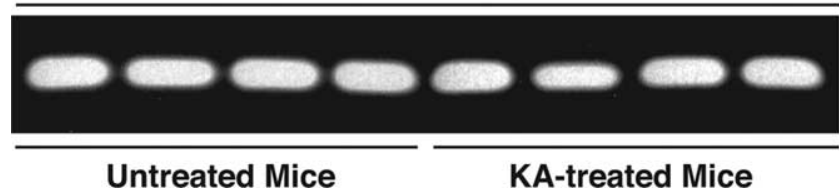

Figure 7. ApoE-13 expression is inversely correlated with apoE expression in mouse hippocampus in response to excitotoxic injury. $\boldsymbol{A}$, In situ hybridization of apoE mRNA showed positive signals in injured CA1 neurons in a kainic acid (KA)-treated mouse. $\boldsymbol{B}$, In situ hybridization of apoE-13 mRNA showed the opposite pattern to that of apoE mRNA (e.g., negative signals of apoE-13 mRNA in degenerating (A1 neurons). C, H\&E staining showed neurodegeneration in the CA1 region, but not in CA3 or the dentate gyrus. D, RT-PCR of apoE and apoE-I3 in EGFP-negative CA1 neurons collected from untreated apoE4/EGFP apoE reporter mice $(n=4)$ by LCM. E, RT-PCR of apoE and apoE-I3 in EGFP-positive CA1 neurons collected from KA-treated apoE4/EGFP ${ }_{\text {apo }}$ mice $(n=4)$ by LCM. $F$, RT-PCR of GAPDH in EGFP-negative and EGFP-positive CA1 neurons collected from untreated and KA-treated apoE4/EGFP ${ }_{\text {apoE }}$ mice $(n=4)$, respectively, by LCM.

tantly, both cells expressed similar levels of GAPDH (Fig. 7F), indicating the quality of RNA and an appropriate RT-PCR, and did not express GFAP (data not shown), suggesting no significant contamination of astrocytes. Thus, apoE-I3 and apoE mRNA levels are inversely correlated in neurons in vivo.

ApoE-I3 is likely a precursor of apoE mRNA

Next, we determined whether apoE-I3 functions as a noncoding RNA that regulates neuronal expression of apoE or as a precursor
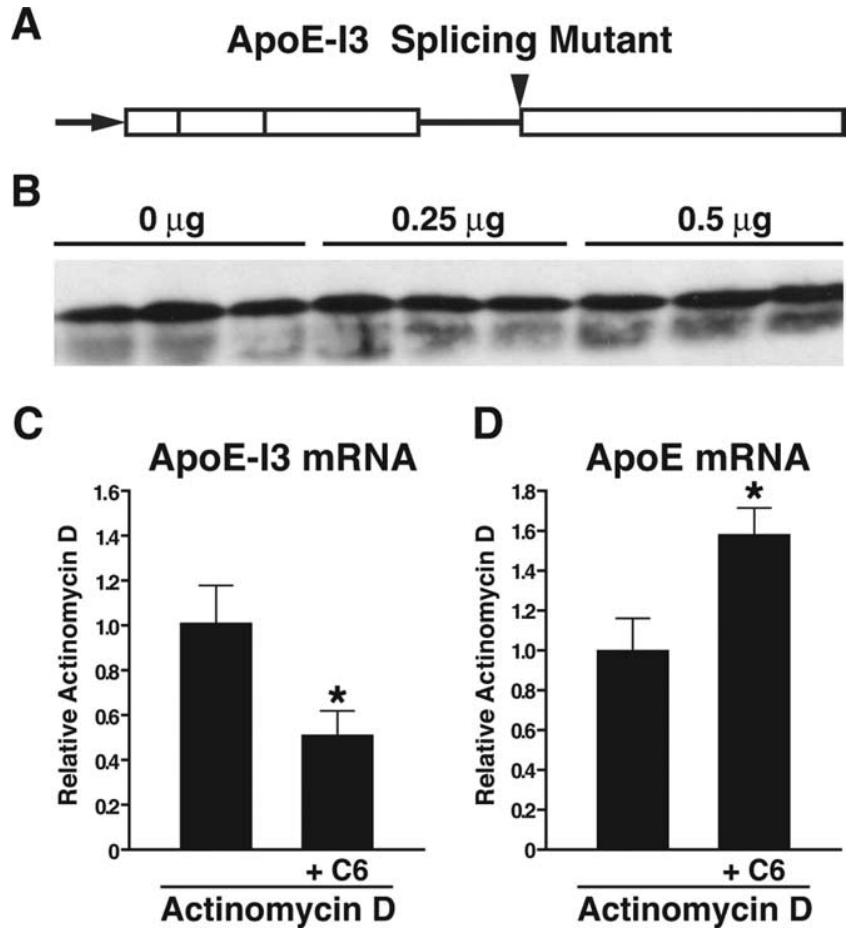

Figure 8. ApoE-I3 is a precursor of apoE mRNA. A, A schematic model of an unspliceable apoE-I3 CDNA construct, in which the splicing acceptor site of intron-3 was mutated to eliminate the splicing. $\boldsymbol{B}$, Neuro-2a cells stably expressing apoE4 from a wild-type genomic DNA construct were transfected with different amounts of the unspliceable apoE-I3 CDNA construct. Intracellular apo E protein levels were determined by anti-apoEWestern blotting $24 \mathrm{~h}$ after transfection. C, D, Primary hippocampal neurons from human apoE4 knock-in mice were cultured in vitro for $14 \mathrm{~d}$ and then treated with the transcription inhibitor actinomycin $\mathrm{D}$ for $6 \mathrm{~h}$, and apoE expression was then induced with astrocyte-conditioned medium. The levels of apoE-I3 (C) and apoE (D) mRNA were quantified by qRT-PCR $\left(n=6 ;{ }^{*} p<0.01\right.$ vs actinomycin D).

of apoE mRNA. First, the splicing acceptor site of intron-3 in the apoE-I3-cDNA construct was mutated to eliminate the splicing of intron-3 (Fig. 8A). In transfected Neuro-2a cells, this mutant construct was transcribed into an mRNA with intron- 3 retention, without protein translation (data not shown). Importantly, apoE expression was not significantly altered by transfection of the mutant construct at different doses into Neuro-2a cells stably expressing apoE4 from a genomic DNA construct (Fig. 8A,B). Thus, it is unlikely that apoE-I3 is a noncoding RNA that regulates neuronal expression of apoE.

To determine whether apoE-I3 is a precursor of apoE mRNA, we cultured primary hippocampal neurons from human apoE4 knock-in mice for $14 \mathrm{~d}$, treated them with the transcription inhibitor actinomycin $\mathrm{D}$ for $6 \mathrm{~h}$, and induced apoE expression with astrocyte-conditioned medium. ApoE-I3 mRNA levels decreased and apoE mRNA levels increased, despite the transcription inhibition (Fig. $8 C, D$ ). These results suggest that apoE-I3 is likely a precursor of apoE mRNA and that the astrocyte-derived factor (or factors) upregulates neuronal expression of apoE by stimulating the processing of apoE-I3 into apoE mRNA.

\section{Discussion}

This study shows that intron-3 retention governs apoE expression in CNS neurons. This finding suggests a model in which neuronal expression of apoE is controlled by two switches (Fig. 9). The first, transcription of the apoE gene, is constitutively on under normal conditions and generates apoE-I3 that is retained in the nucleus and is not translated. The second switch, the pro- 


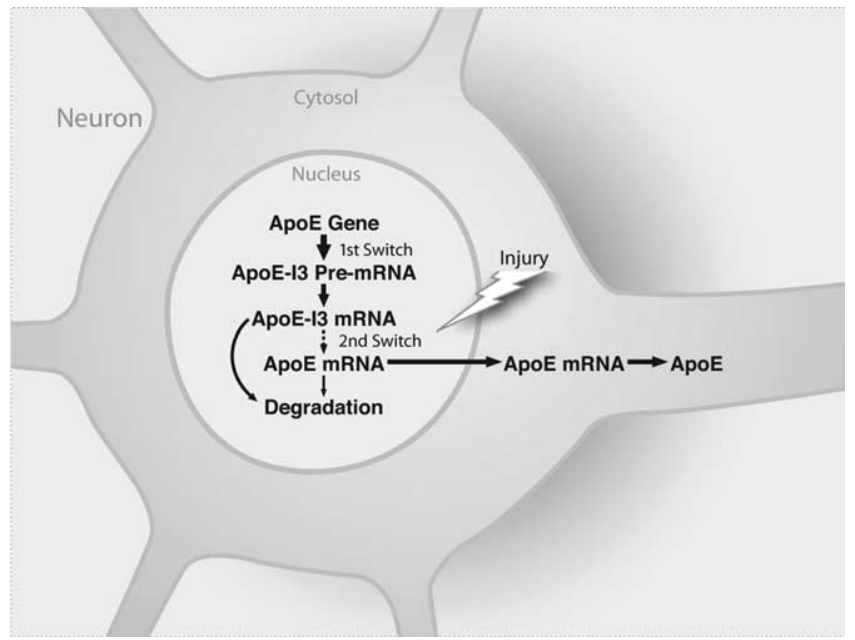

Figure 9. A "two-switch" model for the control of neuronal expression of apoE. The first switch, transcription of the apoE gene, is constitutively on and generates apoE-I3 under normal conditions. The apoE- 13 is retained in the nucleus and is not translated. The second switch, the processing of apoE-I3 into mature apoE mRNA, is turned on in response to neuronal injury.

cessing of apoE-I3 into mature apoE mRNA, is turned on in response to neuronal injury. Although the mechanisms and molecules that control the processing of apoE-I3 into apoE mRNA remain to be elucidated, our findings reveal a novel mechanism underlying the control of apoE expression in CNS neurons.

Previously, three alternative transcripts of the apoE gene in humans and mice were reported (Seitz et al., 2005). Although the $5^{\prime}$ - and $3^{\prime}$-ends of those transcripts were not clearly defined by $5{ }^{\prime}$ and $3^{\prime}$-RACE, the apoE-I3 mRNA we identified does not match those transcripts. Thus, it appears to be a novel alternative transcript of the apoE gene. Interestingly, the 5' (GU) and 3' (AG) splicing sites of apoE intron-3 are optimal for canonical splicing and conserved among human, chimp, baboon, mouse, rat, and pig, suggesting that the intron-3 retention of apoE is not caused by suboptimal splicing sites.

Intron retention of alternative transcripts has been demonstrated in $5-15 \%$ of genes, as shown by genome-wide screening in humans and mice (Kan et al., 2002; Galante et al., 2004). Although some retained introns are translated, others are not and participate in the regulation of gene expression, including proinsulin (Mansilla et al., 2005), cyclooxygenase-1 (Cui et al., 2004; Qin et al., 2005), mitochondrial transcription termination factor (Li et al., 2005), gonadotropin-releasing hormone (Seong et al., 1999), and phenylethanolamine $N$-methyltransferase (Unsworth et al., 1999). Our findings show that apoE-I3 is an untranslated precursor of mature apoE mRNA and that neuronal expression of apoE is controlled by intron-3 retention/splicing. These findings raise several important questions. Do neurons have an intron-3-specific splicing inhibitor or lack an intron-3-specific splicing factor under normal conditions? What signaling pathway links neuronal injury to the activation of intron-3 splicing, and how is this pathway regulated by an astrocytederived factor (or factors)?

Another question is why neurons control apoE expression by intron-3 retention/splicing. Previously, we and others demonstrated that neurons produce apoE quickly in response to injury (Boschert et al., 1999; Xu et al., 2006). Because protein is produced more rapidly from pre-existing mRNA than from transcription of a gene, it is conceivable that apoE-I3 mRNA enables neurons to respond quickly to injury by making apoE immediately available for neuronal repair and remodeling. Because only injured neurons generate apoE from the processing of apoE-I3 mRNA, this might not add significant abundance, compared with those generated in astrocytes, into the overall pool of brain apoE. However, neuron-generated apoE may play important roles intracellularly in neuronal maintenance and repair. Furthermore, because neuron-generated apoE4 has many detrimental effects (Huang et al., 2004, 2006a,b; Mahley et al., 2006), inhibiting neuronal expression of apoE might be beneficial for $\mathrm{AD}$ patients carrying apoE4. This might be achieved by inhibiting the processing of apoE-I3 to mature apoE mRNA. Because apoE-I3 retention is a neuron-specific event, it could be targeted therapeutically without affecting apoE expression in other cells.

\section{References}

Alberts MJ, Graffagnino C, McClenny C, DeLong D, Strittmatter W, Saunders AM, Roses AD (1995) ApoE genotype and survival from intracerebral haemorrhage. Lancet 346:575.

Bales KR, Verina T, Cummins DJ, Du Y, Dodel RC, Saura J, Fishman CE, DeLong CA, Piccardo P, Petegnief V, Ghetti B, Paul SM (1999) Apolipoprotein $\mathrm{E}$ is essential for amyloid deposition in the $A P P^{V 717 F}$ transgenic mouse model of Alzheimer's disease. Proc Natl Acad Sci USA 96:15233-15238.

Boschert U, Merlo-Pich E, Higgins G, Roses AD, Catsicas S (1999) Apolipoprotein E expression by neurons surviving excitotoxic stress. Neurobiol Dis 6:508-514.

Brecht WJ, Harris FM, Chang S, Tesseur I, Yu GQ, Xu Q, Fish JD, Wyss-Coray T, Buttini M, Mucke L, Mahley RW, Huang Y (2004) Neuron-specific apolipoprotein E4 proteolysis is associated with increased tau phosphorylation in brains of transgenic mice. J Neurosci 24:2527-2534.

Buttini M, Orth M, Bellosta S, Akeefe H, Pitas RE, Wyss-Coray T, Mucke L, Mahley RW (1999) Expression of human apolipoprotein E3 or E4 in the brains of Apoe-/- mice: isoform-specific effects on neurodegeneration. J Neurosci 19:4867-4880.

Buttini M, Yu GQ, Shockley K, Huang Y, Jones B, Masliah E, Mallory M, Yeo T, Longo FM, Mucke L (2002) Modulation of Alzheimer-like synaptic and cholinergic deficits in transgenic mice by human apolipoprotein $\mathrm{E}$ depends on isoform, aging, and overexpression of amyloid $\beta$ peptides but not on plaque formation. J Neurosci 22:10539-10548.

Chang S, Ma TR, Miranda RD, Balestra ME, Mahley RW, Huang Y (2005) Lipid- and receptor-binding regions of apolipoprotein E4 fragments act in concert to cause mitochondrial dysfunction and neurotoxicity. Proc Natl Acad Sci USA 102:18694-18699.

Corder EH, Saunders AM, Strittmatter WJ, Schmechel DE, Gaskell PC, Small GW, Roses AD, Haines JL, Pericak-Vance MA (1993) Gene dose of apolipoprotein E type 4 allele and the risk of Alzheimer's disease in late onset families. Science 261:921-923.

Cui J-G, Kuroda H, Chandrasekharan NV, Pelaez RP, Simmons DL, Bazan NG, Lukiw WJ (2004) Cyclooxygenase-3 gene expression in Alzheimer hippocampus and in stressed human neural cells. Neurochem Res 29:1731-1737.

Galante PAF, Sakabe NJ, Kirschbaum-Slager N, de Souza SJ (2004) Detection and evaluation of intron retention events in the human transcriptome. RNA 10:757-765.

Grehan S, Tse E, Taylor JM (2001) Two distal downstream enhancers direct expression of the human apolipoprotein E gene to astrocytes in the brain. J Neurosci 21:812-822.

Harris FM, Brecht WJ, Xu Q, Tesseur I, Kekonius L, Wyss-Coray T, Fish JD, Masliah E, Hopkins PC, Scearce-Levie K, Weisgraber KH, Mucke L, Mahley RW, Huang Y (2003) Carboxyl-terminal-truncated apolipoprotein E4 causes Alzheimer's disease-like neurodegeneration and behavioral deficits in transgenic mice. Proc Natl Acad Sci USA 100:10966-10971.

Harris FM, Brecht WJ, Xu Q, Mahley RW, Huang Y (2004a) Increased tau phosphorylation in apolipoprotein E4 transgenic mice is associated with activation of extracellular signal-regulated kinase: modulation by zinc. J Biol Chem 279:44795-44801.

Harris FM, Tesseur I, Brecht WJ, Xu Q, Mullendorff K, Chang S, Wyss-Coray T, Mahley RW, Huang Y (2004b) Astroglial regulation of apolipoprotein E expression in neuronal cells. Implications for Alzheimer's disease. J Biol Chem 279:3862-3868.

Holtzman DM, Bales KR, Tenkova T, Fagan AM, Parsadanian M, Sartorius 
LJ, Mackey B, Olney J, McKeel D, Wozniak D, Paul SM (2000) Apolipoprotein $\mathrm{E}$ isoform-dependent amyloid deposition and neuritic degeneration in a mouse model of Alzheimer's disease. Proc Natl Acad Sci USA 97:2892-2897.

Huang Y (2006a) Apolipoprotein E and Alzheimer disease. Neurology 66 [Suppl 1]:S79-S85.

Huang Y (2006b) Molecular and cellular mechanisms of apolipoprotein E4 neurotoxicity and potential therapeutic strategies. Curr Opin Drug Discov Dev 9:627-641.

Huang Y, Liu XQ, Wyss-Coray T, Brecht WJ, Sanan DA, Mahley RW (2001) Apolipoprotein E fragments present in Alzheimer's disease brains induce neurofibrillary tangle-like intracellular inclusions in neurons. Proc Natl Acad Sci USA 98:8838-8843.

Huang Y, Weisgraber KH, Mucke L, Mahley RW (2004) Apolipoprotein E. Diversity of cellular origins, structural and biophysical properties, and effects in Alzheimer's disease. J Mol Neurosci 23:189-204.

Ji ZS, Miranda RD, Newhouse YM, Weisgraber KH, Huang Y, Mahley RW (2002) Apolipoprotein E4 potentiates amyloid $\beta$ peptide-induced lysosomal leakage and apoptosis in neuronal cells. J Biol Chem 277:21821-21828.

Kan Z, States D, Gish W (2002) Selecting for functional alternative splices in ESTs. Genome Res 12:1837-1845.

Kantarci OH, Hebrink DD, Achenbach SJ, Pittock SJ, Altintas A, SchaeferKlein JL, Atkinson EJ, de Andrade M, McMurray CT, Rodriguez M, Weinshenker BG (2004) Association of APOE polymorphisms with disease severity in MS is limited to women. Neurology 62:811-814.

Lacomblez L, Doppler V, Beucler I, Costes G, Salachas F, Raisonnier A, Le Forestier N, Pradat PF, Bruckert E, Meininger V (2002) APOE: a potential marker of disease progression in ALS. Neurology 58:1112-1114.

Li X, Zhang LS, Guan MX (2005) Cloning and characterization of mouse mTERF encoding a mitochondrial transcriptional termination factor. Biochem Biophys Res Commun 326:505-510.

Li YJ, Hauser MA, Scott WK, Martin ER, Booze MW, Qin XJ, Walter JW, Nance MA, Hubble JP, Koller WC, Pahwa R, Stern MB, Hiner BC, Jankovic J, Goetz CG, Small GW, Mastaglia F, Haines JL, Pericak-Vance MA, Vance JM (2004) Apolipoprotein E controls the risk and age at onset of Parkinson disease. Neurology 62:2005-2009.

Mahley RW (1988) Apolipoprotein E: cholesterol transport protein with expanding role in cell biology. Science 240:622-630.

Mahley RW, Weisgraber KH, Huang Y (2006) Apolipoprotein E4: a causative factor and therapeutic target in neuropathology, including Alzheimer's disease. Proc Natl Acad Sci USA 103:5644-5651.

Mansilla A, López-Sánchez C, de la Rosa EJ, García-Martínez V, MartínezSalas E, de Pablo F, Hernández-Sánchez C (2005) Developmental regulation of a proinsulin messenger RNA generated by intron retention. EMBO Rep 6:1182-1187.

Masliah E, Westland CE, Rockenstein EM, Abraham CR, Mallory M, Veinberg I, Sheldon E, Mucke L (1997) Amyloid precursor proteins protect neurons of transgenic mice against acute and chronic excitotoxic injuries in vivo. Neuroscience 78:135-146.

Moulard B, Sefiani A, Laamri A, Malafosse A, Camu W (1996) Apolipoprotein E genotyping in sporadic amyotrophic lateral sclerosis: evidence for a major influence on the clinical presentation and prognosis. J Neurol Sci 139 (Suppl.):34-37.

Nishio M, Kohmura E, Yuguchi T, Nakajima Y, Fujinaka T, Akiyama C, Iwata A, Yoshimine T (2003) Neuronal apolipoprotein E is not synthesized in neuron after focal ischemia in rat brain. Neurol Res 25:390-394.

Page KJ, Hollister RD, Hyman BT (1998) Dissociation of apolipoprotein and apolipoprotein receptor response to lesion in the rat brain: an in situ hybridization study. Neuroscience 85:1161-1171.

Pitas RE, Boyles JK, Lee SH, Foss D, Mahley RW (1987) Astrocytes synthesize apolipoprotein $\mathrm{E}$ and metabolize apolipoprotein E-containing lipoproteins. Biochim Biophys Acta 917:148-161.

Qin N, Zhang SP, Reitz TL, Mei JM, Flores CM (2005) Cloning, expression, and functional characterization of human cyclooxygenase-1 splicing variants: evidence for intron 1 retention. J Pharmacol Exp Ther 315:1298-1305.

Raber J, Wong D, Buttini M, Orth M, Bellosta S, Pitas RE, Mahley RW, Mucke $\mathrm{L}$ (1998) Isoform-specific effects of human apolipoprotein E on brain function revealed in ApoE knockout mice: increased susceptibility of females. Proc Natl Acad Sci USA 95:10914-10919.

Raber J, Bongers G, LeFevour A, Buttini M, Mucke L (2002) Androgens protect against apolipoprotein E4-induced cognitive deficits. J Neurosci 22:5204-5209.

Saunders AM, Strittmatter WJ, Schmechel D, St George-Hyslop PH, PericakVance MA, Joo SH, Rosi BL, Gusella JF, Crapper-MacLachlan DR, Alberts MJ, Hulette C, Crain B, Goldgaber D, Roses AD (1993) Association of apolipoprotein $\mathrm{E}$ allele $\varepsilon 4$ with late-onset familial and sporadic Alzheimer's disease. Neurology 43:1467-1472.

Schmidt S, Barcellos LF, DeSombre K, Rimmler JB, Lincoln RR, Bucher P, Saunders AM, Lai E, Martin ER, Vance JM, Oksenberg JR, Hauser SL, Pericak-Vance MA, Haines JL (2002) Association of polymorphisms in the apolipoprotein E region with susceptibility to and progression of multiple sclerosis. Am J Hum Genet 70:708-717.

Seitz A, Gourevitch D, Zhang XM, Clark L, Chen P, Kragol M, Levenkova N, Rux J, Samulewicz S, Heber-Katz E (2005) Sense and antisense transcripts of the apolipoprotein E gene in normal and apoE knockout mice, their expression after spinal cord injury and corresponding human transcripts. Hum Mol Genet 14:2661-2670.

Seong JY, Park S, Kim K (1999) Enhanced splicing of the first intron from the gonadotropin-releasing hormone $(\mathrm{GnRH})$ primary transcript is a prerequisite for mature GnRH messenger RNA: presence of GnRH neuronspecific splicing factors. Mol Endocrinol 13:1882-1895.

Slooter AJ, Tang MX, van Duijn CM, Stern Y, Ott A, Bell K, Breteler MM, Van Broeckhoven C, Tatemichi TK, Tycko B, Hofman A, Mayeux R (1997) Apolipoprotein E $\varepsilon 4$ and the risk of dementia with stroke. A populationbased investigation. J Am Med Assoc 277:818-821.

Speckmann W, Narayanan A, Terns R, Terns MP (1999) Nuclear retention elements of U3 small nucleolar RNA. Mol Cell Biol 19:8412-8421.

Strittmatter WJ, Saunders AM, Schmechel D, Pericak-Vance M, Enghild J, Salvesen GS, Roses AD (1993) Apolipoprotein E: High-avidity binding to $\beta$-amyloid and increased frequency of type 4 allele in late-onset familial Alzheimer disease. Proc Natl Acad Sci USA 90:1977-1981.

Teasdale GM, Nicoll JAR, Murray G, Fiddes M (1997) Association of apolipoprotein E polymorphism with outcome after head injury. Lancet 350:1069-1071.

Tesseur I, Van Dorpe J, Spittaels K, Van den Haute C, Moechars D, Van Leuven F (2000) Expression of human apolipoprotein E4 in neurons causes hyperphosphorylation of protein tau in the brains of transgenic mice. Am J Pathol 156:951-964.

Tolar M, Marques MA, Harmony JAK, Crutcher KA (1997) Neurotoxicity of the $22 \mathrm{kDa}$ thrombin-cleavage fragment of apolipoprotein $\mathrm{E}$ and related synthetic peptides is receptor-mediated. J Neurosci 17:5678-5686.

Tolar M, Keller JN, Chan S, Mattson MP, Marques MA, Crutcher KA (1999) Truncated apolipoprotein E (apoE) causes increased intracellular calcium and may mediate apoE neurotoxicity. J Neurosci 19:7100-7110.

Uchihara T, Duyckaerts C, He Y, Kobayashi K, Seilhean D, Amouyel P, Hauw J-J (1995) ApoE immunoreactivity and microglial cells in Alzheimer's disease brain. Neurosci Lett 195:5-8.

Unsworth BR, Hayman GT, Carroll A, Lelkes PI (1999) Tissue-specific alternative mRNA splicing of phenylethanolamine $N$-methyltransferase (PNMT) during development by intron retention. Int J Dev Neurosci 17:45-55.

Weisgraber KH, Mahley RW (1996) Human apolipoprotein E: the Alzheimer's disease connection. FASEB J 10:1485-1494.

Wisniewski T, Castaño EM, Golabek A, Vogel T, Frangione B (1994) Acceleration of Alzheimer's fibril formation by apolipoprotein E in vitro. Am J Pathol 145:1030-1035.

Xu PT, Gilbert JR, Qiu HL, Ervin J, Rothrock-Christian TR, Hulette C, Schmechel DE (1999) Specific regional transcription of apolipoprotein E in human brain neurons. Am J Pathol 154:601-611.

Xu Q, Li Y, Cyras C, Sanan DA, Cordell B (2000) Isolation and characterization of apolipoproteins from murine microglia. Identification of a low density lipoprotein-like apolipoprotein J-rich but E-poor spherical particle. J Biol Chem 275:31770-31777.

Xu Q, Bernardo A, Walker D, Kanegawa T, Mahley RW, Huang Y (2006) Profile and regulation of apolipoprotein E (apoE) expression in the CNS in mice with targeting of green fluorescent protein gene to the apoE locus. J Neurosci 26:4985-4994.

Ye S, Huang Y, Müllendorff K, Dong L, Giedt G, Meng EC, Cohen FE, Kuntz ID, Weisgraber KH, Mahley RW (2005) Apolipoprotein (apo) E4 enhances amyloid $\beta$ peptide production in cultured neuronal cells: ApoE structure as a potential therapeutic target. Proc Natl Acad Sci USA 102: $18700-18705$. 